Journal of Advanced Research in Fluid Mechanics and Thermal Sciences

\title{
A New Roll and Pitch Control Mechanism for an Underwater Glider
}

\author{
Kesavan Panjavarnam ${ }^{1,}{ }^{*}$, Mark Ovinis ${ }^{1}$, Saravanan Karupanan ${ }^{1}$ \\ 1 Department of Mechanical Engineering, Faculty of Engineering, Universiti Teknologi Petronas, 32610 Bandar Seri Iskandar, Perak, Malaysia
}

\section{ARTICLE INFO}

\section{Article history:}

Received 10 May 2021

Received in revised form 13 June 2021

Accepted 20 June 2021

Available online 4 August 2021

Keywords:

Underwater Glider; Pitch Control; Roll Control

\section{ABSTRACT}

In this paper, a new roll and pitch control mechanism for an underwater glider is described. The mechanism controls the glider's pitch and roll without the use of a conventional buoyancy engine or movable mass. It uses water as trim mass, with a high flow rate water pump to shift water from water bladders located at the front, rear, left, and right of the glider. By shifting water between the left and right water bladder, a roll moment is induced. Similarly, pitch is achieved by shifting water between the front and rear water bladders. The water bladders act not only as a means for roll and pitch control but as a buoyancy engine as well. This eliminates the use of a dedicated mechanism for pitch and roll, thereby improving gliding efficiency and energy consumption, as the glider's overall size is decreased since the hardware required is reduced. The dynamics of the system were derived and simulated, as well as validated experimentally. The glider is able to move in a sawtooth pattern with a maximum pitch angle of $43.5^{\circ}$, as well as a maximum roll angle of $43.6^{\circ}$ with pitch and roll rates increase with increasing pump rate.

\section{Introduction}

An Autonomous Underwater Vehicle (AUV) is an underwater robot typically used for oceanology $[1,2]$. Oceanographers often use gliders to collect physicochemical data at the subseafloor such as salinity, temperature, and oxygen level [3]. Furthermore, gliders are used for military missions as well. Sensors on the glider detected and registered data, which was then transmitted to an offshore location via satellite connections.

These gliders are usually integrated with advanced control systems that allow the glider to move independently to a predetermined depth based on GPS navigation. They use variable-buoyancy propulsion instead of traditional propellers or thrusters and can convert vertical motion into horizontal motion using wings [4,5]. Slocum was developed to travel up to $600 \mathrm{~km}$ using a buoyancy pump and wings to convert the vertical motion into horizontal with a gliding angle and speed of $35^{\circ}$ and $0.25 \mathrm{~m} / \mathrm{s}[3,7]$. This inspired the development of various types of gliders such as the Spray Glider, Seaglider, ROUGHIE, ALBAC, Petrel-II, Grace, Hybrid Underwater Glider, USM Underwater Glider,

\footnotetext{
* Corresponding author.

E-mail address: kesavan_19001008@utp.edu.my.com
}

https://doi.org/10.37934/arfmts.85.1.143160 
Underwater Glider Mk.III, Miniature Underwater Glider and Starfish, each with differences in design and configuration [7-11,13-15,20,22,24\}.

The Spray glider has a rack-and-pinion mechanism with a DC motor that is used to shift its battery mass and a hydraulic system in the rear section to control its gliding motion. It has a gliding speed of $0.28 \mathrm{~m} / \mathrm{s}$ at a pitch angle of $20.1^{\circ}$. Roll motion is induced by rotating the battery mass about 360 degrees around the axial column $[6,7]$. Seaglider model uses a planetary gear system that drives a linear actuator to change the glider's center of gravity by shifting the battery pack linearly or rotating it and is capable of a maximum pitch angle of $45^{\circ}$ and maximum roll angle of $30^{\circ}$ [8]. It is also equipped with a hydraulic system to control the buoyancy amount, by displacing the fluid between the inner and outer reservoir. It is designed to travel in a sawtooth pattern with a gliding speed of $0.25 \mathrm{~m} / \mathrm{s}$ [8].

Aside from these legacy gliders, the ROUGHIE was designed with common coupled mechanisms which controlled the pitch by shifting a $2.2 \mathrm{~kg}$ battery mass linearly, with buoyancy controlled by a buoyancy engine. The roll mechanism is an aluminum ring attached to an internal hull surface, with a moveable mass that is driven by a servo motor. In a neutrally buoyant state, ROUGHIE is able to roll more than $60^{\circ}$ [9].

Apart from conventional glider models, Zhang et al., [13] developed a glider that looks like robotic fish (Grace). The glider has a pitch control mechanism that shifts the center of gravity by using a linear actuator with battery mass and controls buoyancy by shifting water in and out of a water tank by using a hydrostatic system. It can move in a saw tooth motion by controlling its pitch angle and can switch to spiral motion by moving its tail fin when required, as well as a combination of both motions to travel in a water column. During pool testing, the Grace had a pitch angle ranging from $20-40$ degrees with a terminal velocity of $0.2 \mathrm{~m} / \mathrm{s}$, while the roll angle range was $10-15$ degrees [13].

In 2018 Dae-Hyeong Ji et al., introduce a hybrid underwater glider model. The glider has an elliptical shape with a controllable thruster to improve gliding speed. Pitch motion is induced by shifting the battery mass linearly, with a ballast tank as a buoyancy engine. The combination of both a conventional buoyancy engine and thruster results in an optimal gliding velocity of $1.2 \mathrm{~m} / \mathrm{s}$ with a pitch angle of $35^{\circ}$. Isa and Arshad [15] developed the USM underwater glider based on a conventional coupled system (sliding mass and ballast pump) with controllable wings and rudder for roll control. It has an average pitch angle of $45.3^{\circ}$ and a roll angle of less than $20^{\circ}$. The glider uses a homeostatic controller to adapt to the biological conditions in the water. However, their experimental and simulation results of the pitch and roll motions are inconsistent along with $24 \%$ of the optimal roll angle error with the roll rate error of more than $5 \mathrm{deg} / \mathrm{s}$ and a maximum pitch rate error of $81.5 \%$ [15].

All the gliders described above move in a saw tooth motion by controlling their pitch angle. Fundamentally, pitch control is achieved by shifting the center of gravity of the glider by moving an internal mass linearly. When the glider reaches a predetermined depth, the glider pitches upwards by pumping water out from the ballast tank and shifting the internal moving mass toward the tail of the glider [5]. Likewise, the glider induces roll motions by shifting the center of gravity from left to right or vice versa $[9,26]$. Underwater gliders therefore use a buoyancy engine and moveable mass for the pitch control and roll control.

Glider structural dimensions such as hull size, overall size and mass are significant to the gliding efficiency and energy consumption [20,22]. In this paper, a single mechanism for pitch and roll control is developed which will enable a reduction in hull size, overall size and mass. The mechanism uses water as trim mass, with water pumps to shift water from water bladders located at the front, rear, left, and right of the glider. By shifting water from the left water bladders to the right water bladders, a roll moment is induced. Similarly, pitch is achieved by controlling the water flow between the front and rear water bladders using a water pump. The water pumps regulate both the amount of buoyancy and the glider's centre of gravity. This implementation eliminates the use of a dedicated mechanism 
for pitch and roll, such as a moveable mass and rotation mechanism in the hull space for the pitch and roll control system. This improves gliding efficiency and energy consumption, as the glider's overall size is decreased, as the hardware required is reduced.

The remainder of this paper is organized as follows. In section 2.1, an overview and the design implementation of the UTP glider model is presented. The related dynamic equations and kinematic equations are shown in section 2.2. Section 3 compares the simulation results to the experimental data, emphasizing the pump actuation system. Finally, section 4 concludes the present work.

\section{Methodology}

\subsection{Design Overview and Implementation of Pitch and Roll Control Modules}

The UTP glider prototype was built using fiberglass, which has better seakeeping capability. It is $1.04 \mathrm{~m}$ in length, has an internal hull with a diameter of $0.2 \mathrm{~m}$ and weighs $26.7 \mathrm{~kg}$. The total mass after assembly is $42 \mathrm{~kg}$. The glider has wings and a rudder to stabilize the gliding motion, as well as to convert vertical movement to horizontal motion [4]. The control mechanisms and related electronic components are assembled in the hull of the glider, as shown in Figure 1.

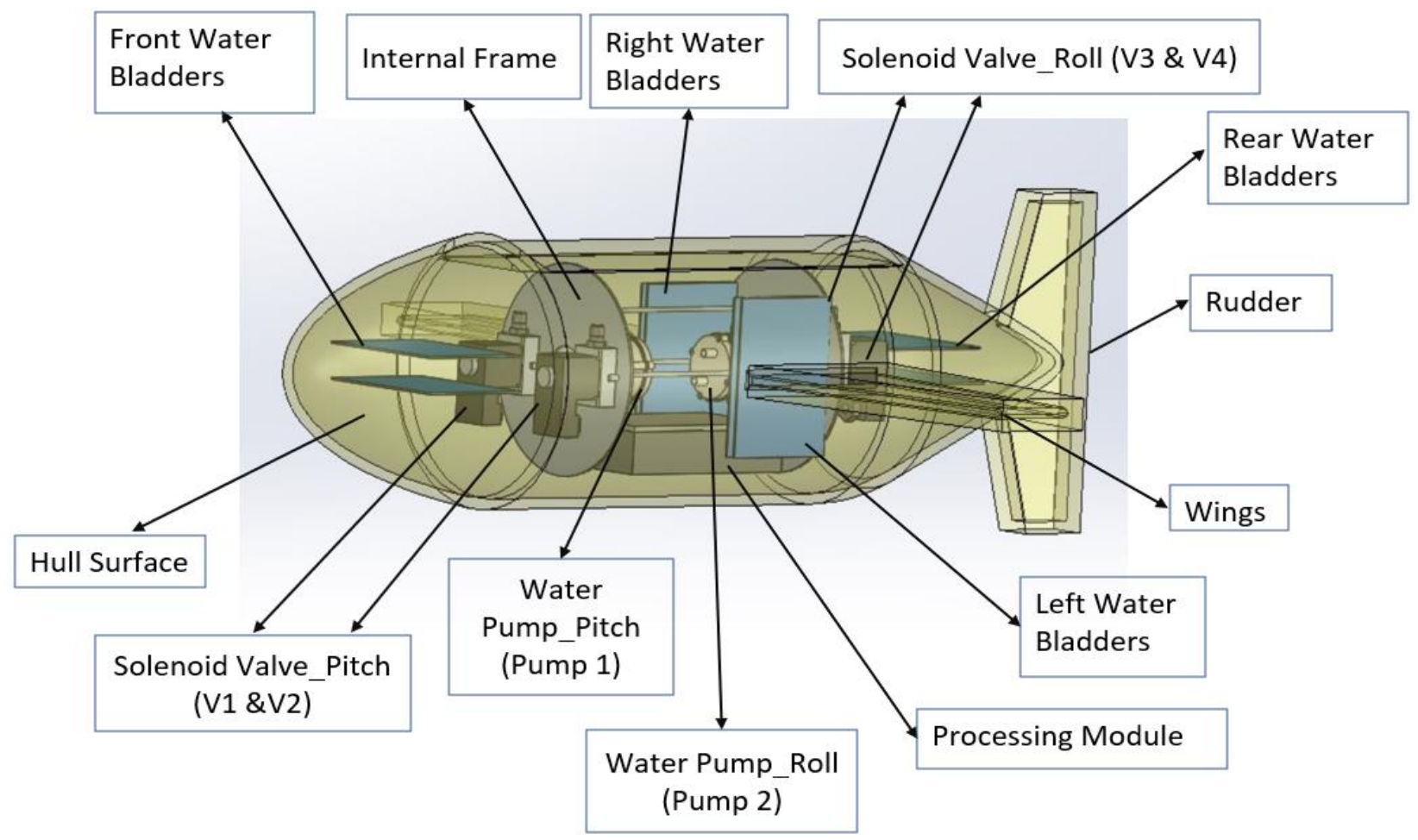

Fig. 1. Overview of the UTP Glider

The assembly of the UTP glider is shown in Figure 2. These fabrication and standard components were used to build the glider with a single actuation system to control pitch and roll individually. Table 1 shows the list of standard key components of the glider. 


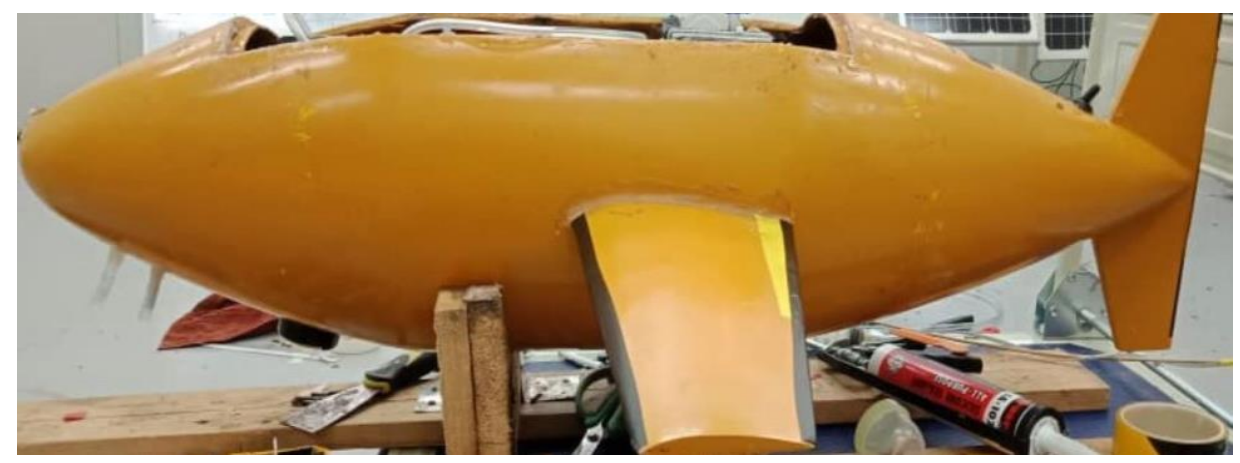

Fig. 2. The UTP Glider

Table 1

Key components used in UTP Glider

\begin{tabular}{ll}
\hline Component Name & Component Model \\
\hline Water Pump & DVA DQB415-SB \\
Water Bladder & E20052 \\
Solenoid Valve (NC) & FELLBACH K222 \\
Battery & 12v GP Battery \\
Microcontroller & Arduino Mega 2560 \\
Pressure sensor & Honeywell \\
& (PX2EF1XX030PAAAX) \\
IMU Unit & MPU 6050 \\
Data logger & Shield-SD-RTC \\
\hline
\end{tabular}

Three different modules are employed; pitch control, roll control and a processing module. Each of the control modules is equipped with an individual control system. The DVA DQB415-SB water pumps are powered by a $12 \mathrm{~V} \mathrm{DC}$ power supply and can transfer up to $2.5 \mathrm{~L} / \mathrm{min}$ of fluid. The pump is small, weighs $100 \mathrm{~g}$ and is mounted on the internal frame. A normally closed (NC) solenoid valve can be triggered by a 12V DC power supply to regulate the flow of water and to maintain the pressure. These water pumps and solenoid valves were fixed to the internal frame at the middle section of the glider's hull surface. The water was pumped into $2 \mathrm{~L}$ water bladders.

The processing module consists of an Arduino Mega 2560 with an ATmega 2560 eight-bit microcontroller with 54 digital input/output pins with a specific function. Other components include a 12 VDC GP battery as a power supply, a MPU 6050 IMU, a Honeywell's pressure sensor with the range of 0 to $30 \mathrm{psi}$, and a data logger with SD card to store relevant measurement data. The IMU unit has a three axis of accelerometer and three axis of gyroscopes and is connected to the Arduino board to acquire pitch and roll data. A Honeywell pressure sensor was used to determine the depth to control the ascent and descent motions based on the predetermined depth levels.

The ascent and descent of the glider is controlled by adjusting the center of gravity and the buoyancy respectively. For pitch control, each of the front and rear hull sections is equipped with two water bladders and both sides are filled with an equal amount of water in steady state condition. The glider pitches downward when water is pumped from the rear water bladders to the front water bladders and pitches upward when the water is displaced towards the rear water bladders. As shown in Figure 3, a water pump with two solenoid valves was applied to control the flow of water. When pump 1 is enabled, its rotation is alternated between CW or CCW, according to the pressure differences at various depth levels. Similarly, both solenoid valves (V1 \& V2) activate alternatively, and the triggering signal is corresponding to the pump 1 signal. 


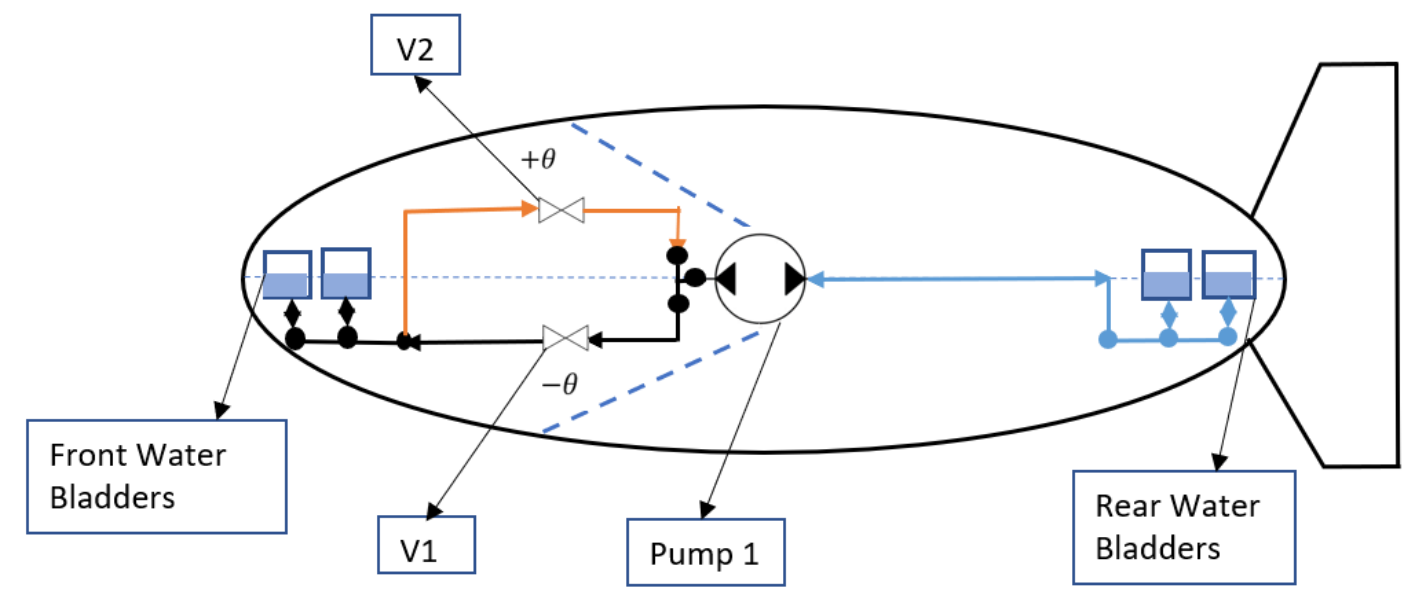

Fig. 3. Schematic of the internal configuration for the pitch control system

The glider trajectory is in sawtooth motion and is divided into four depth levels, which are sensed by the pressure sensor. These are the upper limit, the upper threshold, the lower threshold, and the lower limit. As the changes of the gliding motion is required about $0.4 \mathrm{~m}$ prior to reaching the maximum predetermined depth limit; the pump is reversed counter clockwise (CCW) once it reaches the lower threshold limit during descending motion and changed to clockwise (CW) once it reaches the upper threshold limit during ascending motion. Whereas each ascending and descending gliding motions represent the distinct water column. The depth is calculated using the equations below, where ' $P$ ' pressure in Pascal (Pa), ' $D$ ' is depth in meter $(\mathrm{m}), ' g$ ' is gravity in $\mathrm{m} / \mathrm{s}^{2}$, ' $\rho$ ' is the density in $\mathrm{kg} / \mathrm{m}^{2}$, and ' $\Delta P^{\prime}$ ' is a pressure difference between the pressure at the water surface and the pressure at a given depth.

$$
\begin{aligned}
& P=D \cdot \rho \cdot g \\
& D=\Delta P \times 100 / \rho g
\end{aligned}
$$

Similarly, roll is achieved by shifting the water mass from the left and right water bladders. The roll control module consists of a water pump, two solenoid valves, with each left and right section equipped with two water bladders. The glider's roll angle should remain at $0^{\circ}$ when in equilibrium. Roll is induced by shifting water mass from left to right side or vice versa, which results in the center of gravity of the glider shifting in the ' $y$ ' axis. In this case, pump 2 is activated to displace the water mass based on the IMU signals. Both solenoid valves (V3 \& V4) are triggered alternately, which corresponds to the pump 2 signals to control the flow of water between the water bladders, as shown in Figure 4. 


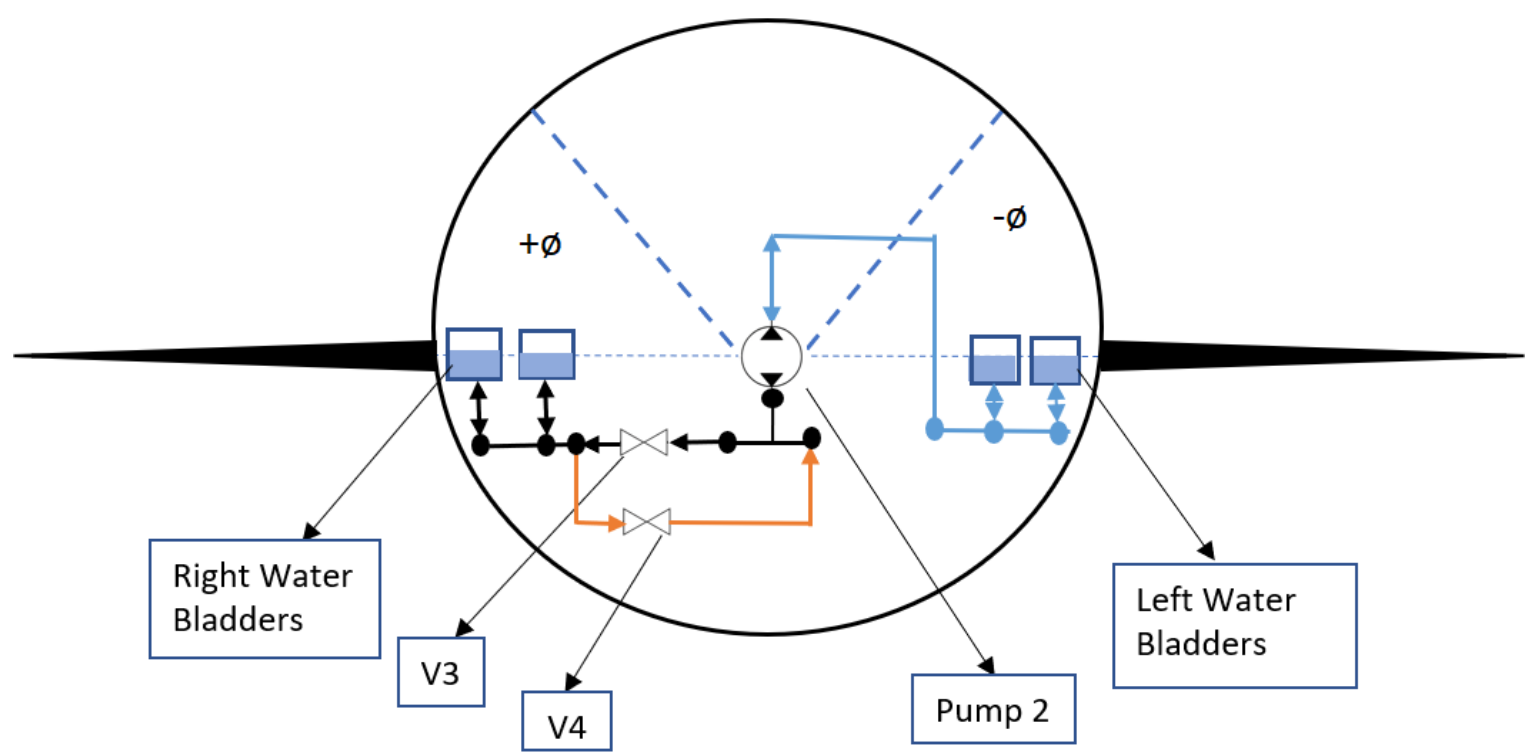

Fig. 4. Schematic of the internal configuration for roll control system

\subsection{Dynamic Modelling for an Underwater Glider}

A mathematical model was used to model the dynamic characteristics of the glider, based on the glider's structure. Hydrodynamic coefficients, hydrodynamic forces, and moments acting on the glider are considered in the equations of motion. At constant speed, the equilibrium condition is used as a reference condition, for expanding the hydrodynamic forces and moments using Taylor's expansion series. Six-coupled non-linear differential equations are used to describe the motion of the underwater glider. Three of these equations describe the translational motion and the remaining three equations describe the rotational motion. Two fixed points are used to determine all the nonlinear differential equations such as the centre of mass (CM), and the centre of buoyancy (CB) of the vehicle. The Earth Fixed coordinate system, Body Fixed coordinate system, and Stream coordinate system are three coordinate systems used in this paper. The center of gravity is the origin coordinate point of the system.

The Body Fixed coordinate frame ' $O$ ' fixed on the geometric center of the glider, while ' $y$ ' axis points towards the starboard, ' $x$ ' falls along the positive direction when the vehicle moves forward, and the direction of the ' $z$ ' axis is determined by the right-hand rule and points downwards towards the gravitational force as shown in Figure $5[19,22]$.

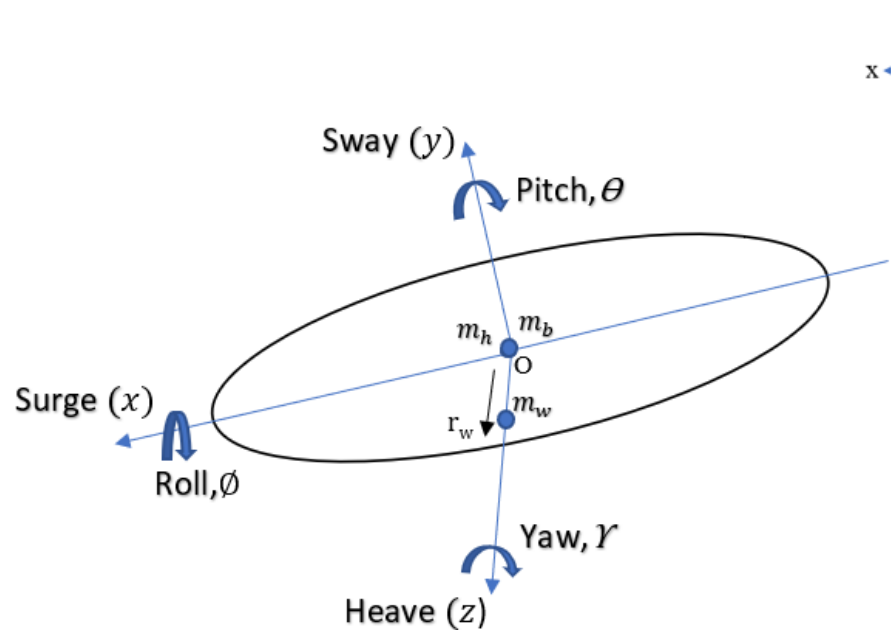

Fig. 5. Coordinate and mass distribution frame 
The glider can move freely and change its orientation. The six DOF equations below are used to represent the translational movement of the glider in the forward/backward (surge), up/down (heave), and left/right (sway) motion. The rotational movement is the yaw, pitch, and roll motion. Based on Eq. (3) below $u, v, w$ represents the translational speed and $p, q, r$ represents the angular speed for the $x, y, z$ axes, respectively. Whereas, $X, Y, Z$ and $K, M, N$ are the external forces and moments on the glider [28].

$$
\begin{aligned}
& m\left[\dot{u}-v r+w q-x_{G}\left(q^{2}+r^{2}\right)+y_{G}(p q+\dot{r})+z_{G}(p r+\dot{q})=X\right. \\
& m\left[\dot{v}-w q+u r-y_{G}\left(r^{2}+p^{2}\right)+z_{G}(q r+\dot{p})+x_{G}(p q+\dot{r})=Y\right. \\
& m\left[\dot{w}-u q+v p-z_{G}\left(p^{2}+q^{2}\right)+x_{G}(p r+\dot{q})+z_{G}(p r+\dot{p})=Z\right. \\
& J_{x x} \dot{p}+\left(J_{z z}-J_{y y}\right) q r-J_{y z}\left(q^{2}-r^{2}\right)+J_{x y}(p r-\dot{q})-J_{z x}(p q+\dot{r})+m\left[y_{G}(\dot{w}-u q+v p)-\right. \\
& \left.z_{G}(\dot{v}-w p+u r)\right]=K \\
& J_{y y} \dot{q}+\left(J_{x x}-J_{z z}\right) p r-J_{z x}\left(r^{2}-p^{2}\right)+J_{y z}(p q-\dot{r})-J_{x y}(q r+\dot{p})+m\left[z_{G}(\dot{u}-v r+w q)-\right. \\
& \left.x_{G}(\dot{w}-u q+v p)\right]=M \\
& J_{z z} \dot{r}+\left(J_{y y}-J_{x x}\right) p q-J_{x y}\left(p^{2}-q^{2}\right)+J_{z y}(q r-\dot{p})-J_{y z}(p r+\dot{p})+m\left[x_{G}(\dot{v}-w p+u r)-\right. \\
& \left.y_{G}(\dot{u}-v r+w q)\right]=N
\end{aligned}
$$

According to Zhou [12] the geometric relationship between the earth fixed coordinate (E-frame) and body fixed coordinate (B-frame) can obtain by the rotational matrix $R_{E B}$. However, the rotational matrix $R_{E B}$ can obtain by multiplication of rotation matrices $R_{\varnothing}\left(\right.$ roll), $R_{\ominus}$ (pitch), and $R \gamma($ yaw).

$$
\begin{aligned}
R_{\emptyset} & =\left[\begin{array}{ccc}
1 & 0 & 0 \\
0 & \cos \emptyset & \sin \emptyset \\
0 & -\sin \emptyset & \cos \emptyset
\end{array}\right] \\
R_{\theta} & =\left[\begin{array}{ccc}
\cos \theta & 0 & -\sin \theta \\
0 & 1 & 0 \\
\sin \theta & 0 & \cos \theta
\end{array}\right] \\
R_{\gamma} & =\left[\begin{array}{ccc}
\cos \gamma & \sin \gamma & 0 \\
-\sin \gamma & \cos \gamma & 0 \\
0 & 0 & 1
\end{array}\right]
\end{aligned}
$$

$R_{E B}=\left[\begin{array}{ccc}\cos \gamma \cos \theta & \sin \gamma \cos \theta & -\sin \theta \\ -\sin \gamma \cos \theta+\cos \gamma \sin \emptyset \sin \emptyset & \cos \gamma \cos \theta+\sin \emptyset \sin \theta \sin \gamma & \cos \theta \sin \emptyset \\ \sin \gamma \sin \emptyset+\cos \gamma \cos \emptyset \sin \theta & -\cos \gamma \sin \emptyset+\sin \theta \sin \gamma \cos \emptyset & \cos \theta \cos \emptyset\end{array}\right]$

The linear displacement and angular velocity of the glider with respect to the Earth Fixed Coordinate system is $V_{e}=[x, y, z]^{T}$ and $\omega_{e}=[\dot{\varnothing}, \dot{\theta}, \dot{\gamma}]^{T}$. The linear velocity and angular velocity of the glider, with respect to the body fixed coordinate system is denoted as $V_{b}=[u, v, w]^{T}$ and $\omega_{b}=$ $[p, q, r]^{T}[4,21]$. Hence, the mathematical expression of the motion of the glider with respect to the earth fixed coordinate system and body fixed coordinate system is shown in Eq. (8). 
$\dot{V}_{e}=R_{E B}{ }^{T} \cdot V_{b}$

The summation of both body fixed coordinate and earth fixed coordinate system gives the linear velocity, as shown in Eq. (9), as well as the angular velocity, as shown in Eq. (10).

$$
\begin{aligned}
& {\left[\begin{array}{c}
\dot{x} \\
\dot{y} \\
\dot{z}
\end{array}\right]=R_{E B}{ }^{T} \cdot\left[\begin{array}{l}
u \\
v \\
w
\end{array}\right]} \\
& \omega_{e}=\left[\begin{array}{c}
\dot{\emptyset} \\
\dot{\theta} \\
\dot{\Upsilon}
\end{array}\right]=\left[\begin{array}{ccc}
1 & 0 & -\sin \theta \\
0 & \cos \emptyset & \cos \theta \sin \theta \\
0 & -\sin \emptyset & \cos \theta \cos \emptyset
\end{array}\right]^{-1}\left[\begin{array}{l}
p \\
q \\
r
\end{array}\right]
\end{aligned}
$$

The net mass $m_{o}$ is given by Eq. (11), where $m_{t}$ is the trim mass and $m_{\text {total }}$ is the glider's mass, which is the sum of uniform glider hull mass $m_{h}$, the point mass to the fixed centre of gravity and buoyancy $\mathrm{m}_{\mathrm{w}}$, and the variable ballast mass with respect to geometry centre (CG) $m_{b}$, as shown in Eq. (12).

$$
\begin{aligned}
& m_{o}=m_{\text {total }}-m_{t} \\
& m_{\text {total }}=m_{h}+m_{w}+m_{b}
\end{aligned}
$$

These equations are used to define the buoyancy condition of the glider. When $m_{o}$ is positive, the glider is negatively buoyant and vice versa. The glider's Center of Gravity (CG) is located below the Center of Buoyancy (CB), which provides a righting moment, which is $\left(X_{g}, Y_{g}, Z_{g}\right)$ components located at the negative Z-axis with respect to the Body-Fixed Frame. The roll motion of the glider occurs when the Center of Gravity (CG) and Center of Buoyancy (CB) are not aligned in the ' $Z$ ' axis, resulting in a torque that causes the glider to rotate. Eq. (13) shows the torque equation, based on Newton's $2^{\text {nd }}$ law of motion $F=m a$. Where $\tau$ is torque, $J$ is the moment of inertia and $\alpha$ is the angular acceleration of the underwater glider.

$\tau=J \alpha$

The sum of roll moments during the glider roll motion is obtained by summing up the hydrostatic righting moment, rolling drag, and rolling added mass as given in Eq. (14) [12]. Hydrostatic righting moment is generated by the buoyancy force and total weight of the glider. The wings and fins result in a rolling drag. Rolling added mass is the mass of the shifted water.

$\Sigma \tau=\left(\tau_{\text {hydro }}+\tau_{\text {AM }}+\tau_{\text {drag }}\right)$

$\tau_{\text {hydro }}=m_{t} \cdot g \cdot r_{t y} \cos \emptyset-m_{t} \cdot g \cdot r_{t z} \sin \emptyset-\left(m_{\text {total }}-m_{t}\right) \cdot g \cdot r_{z} \sin \emptyset$

$m_{t}$ is the trim mass of the roll module and $m_{\text {total }}$ is the nett mass of the glider.

$\tau_{A M}=K_{p} p$

$K_{p}$ is the rolling added mass coefficient and $p$ is the roll angular acceleration. 
$\tau_{d r a g}=K_{p p} \dot{p}|\dot{p}|$

$K_{p p}$ is the rolling quadratic drag coefficient and $\dot{p}$ is the roll angular velocity.

\subsubsection{Hydrodynamic equations}

By referring to Zhou [12], the hydrodynamic equations are derived based on Computational Fluid Dynamics (CFD) simulation to determine the hydrodynamic properties of the underwater glider used in the dynamic simulation [25,27]. The coefficients obtained from CFD simulations are $K_{q 1}, K_{m 1}, K_{q 2}$, $K_{m 0}$, and $K_{m \alpha}$. Eq. (18) and Eq. (19) below shows added roll moment inertia $\left(M_{D L 1}\right)$ and the added pitch moment inertia $\left(M_{D L 2}\right)$.

$$
\begin{aligned}
& M_{D L 1}=K_{m} \beta V^{2}+K_{q 1} p V^{2} \\
& M_{D L 2}=\left(K_{m 0}+K_{m \alpha}+K_{q 2} q\right) V^{2}
\end{aligned}
$$

\subsubsection{Kinematic equations}

The glider's roll angle is zero when in equilibrium. Based on Figure 6, the roll angle is given in Eq. (20) [12]. Eq. (21) and Eq. (22) shows that the roll rate is obtained by integrating the roll angle. The roll rate, $\dot{p}$ can be determined based on the conservation law of angular momentum by integrating the four terms in Eq. (22) [12].

The same equation can be used for pitch rate determination, as the parameters are the same, except for the hydrodynamic coefficients $\left(K_{q 2}\right)$ in added pitch moment inertia $\left(M_{D L 2}\right)$ and moment of inertia $\left(U_{y y}\right)$.

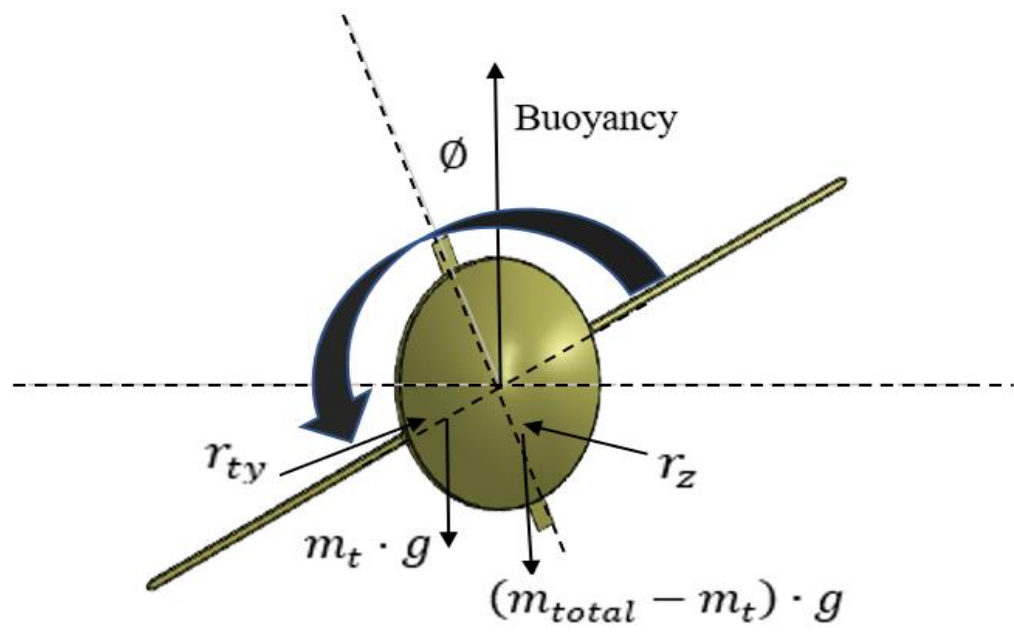

Fig. 6. Front view of UTP Glider

Hydrodynamic non-linear terms in the steady state equation can be linearized by $\cos \emptyset=1$, $\sin \emptyset=\emptyset, \arctan \left(r_{m z} / r_{m y}\right)=r_{m z} / r_{m y} M_{D L 1}=K_{q 1} p V^{2}$ [10].Then, trim weight can be determined by integrating the division of trim weight inertia $p t$ and trim mass $m_{t}$, as shown in Eq. (23).

$\dot{\varnothing}=p$ 
$J_{x x} \dot{p}=m_{t} \cdot g \cdot r_{t y} \cos \emptyset-\left(m_{\text {total }}-m_{t}\right) \cdot g \cdot r_{z} \sin \emptyset+D_{e}+M_{D L 1}$

$\dot{p}=1 / J_{x x}\left(m_{t} \cdot g \cdot r_{t y}-\left(m_{\text {total }}-m_{t}\right) \cdot g \cdot r_{z} \cdot \emptyset+D_{e}+K_{q 1} p V^{2}\right)$

$r_{t y}=p_{t} / m_{t}$

The moment of inertia $J_{x x}, J_{y y}$, total glider mass $m_{\text {total }}$, and trim mass ' $m_{t}$ ' is obtained from the CAD model. Table 2 shows related parameters of the UTP glider.

Table 2

Parameter for the UTP Glider

\begin{tabular}{lll}
\hline Parameters & Description & Values \\
\hline$m_{\text {total }}$ & Total Glider Mass & $42.8 \mathrm{~kg}$ \\
$J_{x x}$ & Moment of Inertia ' $x$ ' axis & $0.7026 \mathrm{~kg} \cdot \mathrm{m}^{2}$ \\
$J_{y y}$ & Moment of Inertia ' $y$ ' axis & $4.507 \mathrm{~kg} \cdot \mathrm{m}^{2}$ \\
$m_{t}$ & Trim Mass & $2.283 \mathrm{~kg}$ \\
$g$ & Gravity & 9.81 \\
$r_{z}$ & $\left(m_{\text {total }}-m_{t}\right)$ CG respect to CB & $-10 \mathrm{~mm}$ \\
$K_{q 1}$ & Hydrodynamic Coefficient & $-20 \mathrm{~kg} \cdot \mathrm{s} / \mathrm{rad}^{2}$ \\
$K_{q 2}$ & Hydrodynamic Coefficient & $-60 \mathrm{~kg} \cdot \mathrm{s} / \mathrm{rad}^{2}$ \\
$V$ & Glider Steady State Velocity & $0.55 \mathrm{~m} / \mathrm{s}$ \\
$M_{D L 1}$ & Added Roll Moment Inertia & -6.05 \\
$M_{D L 2}$ & Added Pitch Moment Inertia & -18.15 \\
\hline
\end{tabular}

The dynamic model of the UTP glider was solved through the Simulink model, as shown in Figure 7 where Eq. (20) to Eq. (23) were applied with the parameters listed in Table 2. The model uses a PID controller block to determine the appropriate pump flow rate for the pitch and roll rates respectively. Four different pump rates (2.5LPM, 5LPM, 7.5LPM and 10LPM) were considered to evaluate the pitch and roll performance of the glider. These pump rates, in multiples of the base pump rate, were chosen to compare the performance with the base pump.

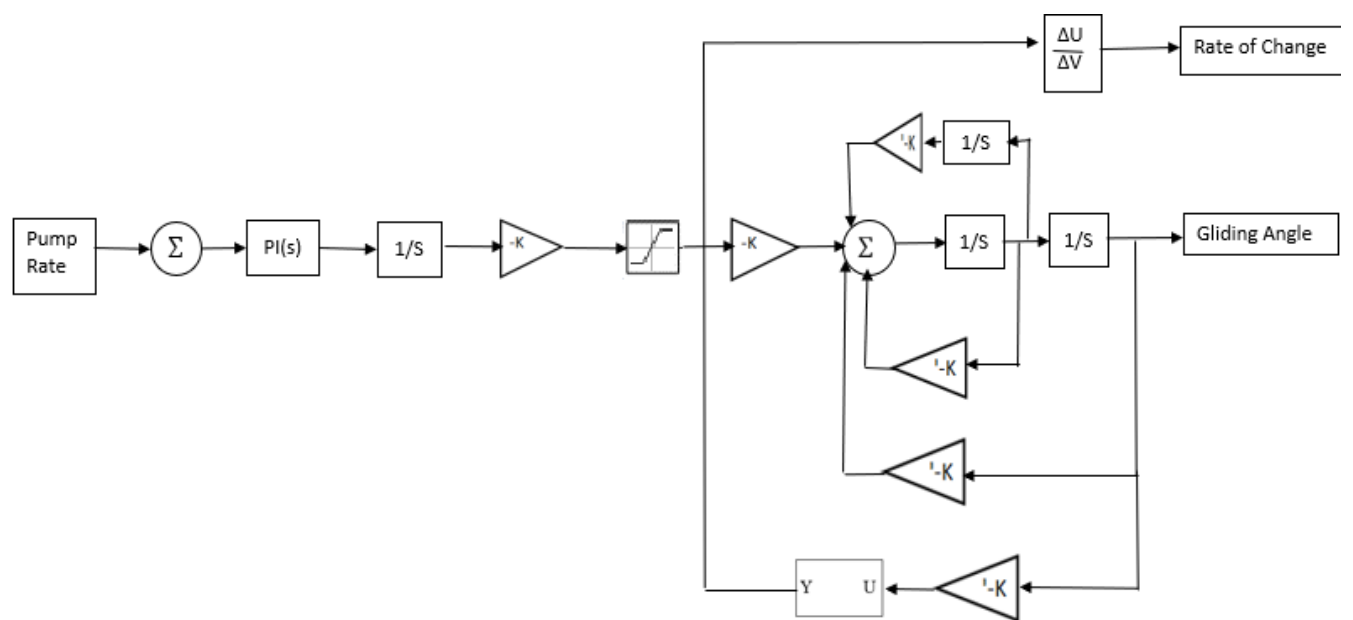

Fig. 7. Block diagram of a Simulink model to determine pitch/roll angle and rate for a given pump flow rate 


\section{Results}

\subsection{Pitch and Roll Test of the UTP Underwater Glider}

A pitch and roll test was conducted in the UTP swimming pool with $3 \mathrm{~m}$ depth. Figure 8 shows the glider pitching upward in a saw tooth pattern and Figure 9 shows the rolling motion, which is achieved by shifting water between the water bladders. The glider tested used 2.5LPM pumps and the data related to the pitch and roll motion was measured using an IMU and stored in a data logger. These experimental data were used to compare with the simulation results, as shown in Figure 12 and Figure 13.

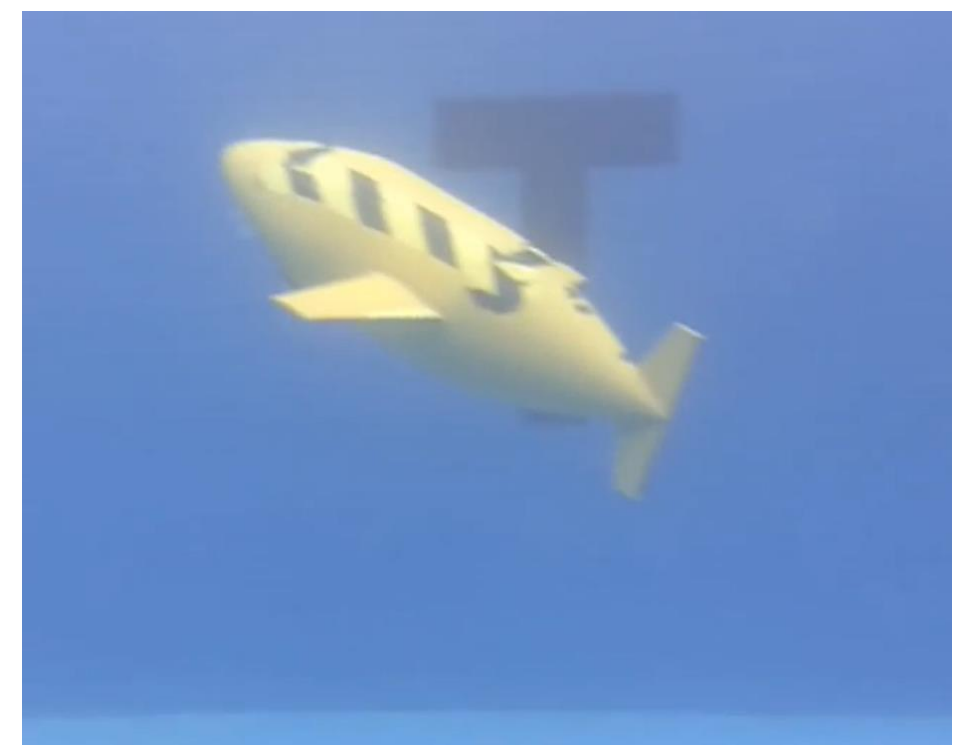

Fig. 8. Pitch motion during the experimental test

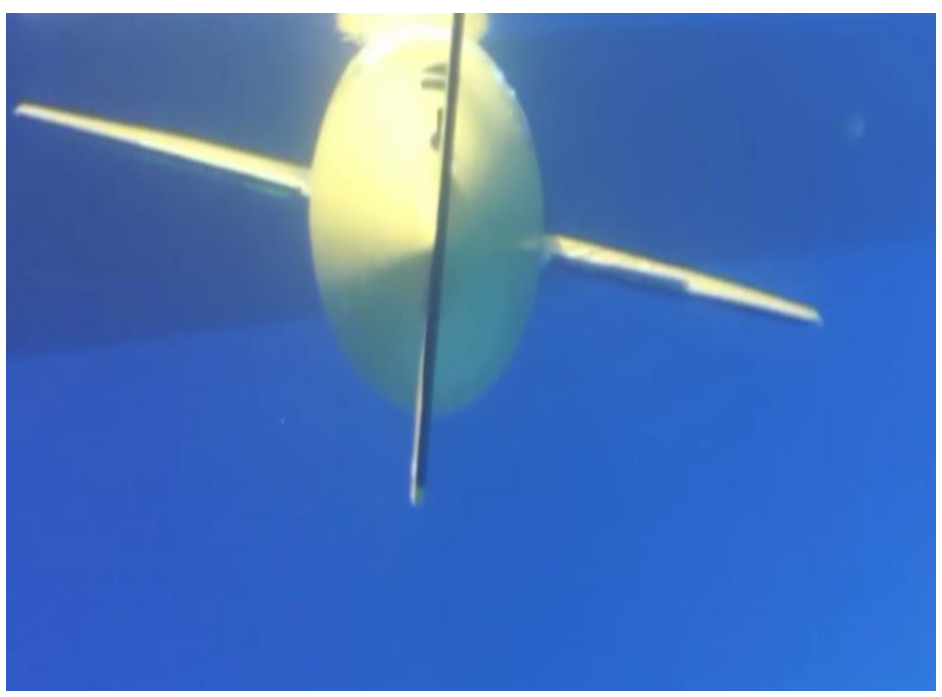

Fig. 9. Roll motion during the experimental test

\subsubsection{Pitch and roll angle}

Both pitch and roll angle was simulated, with the glider capable of reaching a pitch angle of 43.5 degrees and a maximum roll angle of 43.6 degrees, as shown in Figure 10 and Figure 11 . The pitch and roll angle depends on the water mass, as a higher volume of water bladder causes the glider to achieved a higher pitch and roll angle, compared to the lower volume of the water bladder. 
Furthermore, the desired roll angle was achieved within $13 \mathrm{sec}$, which is $16 \mathrm{sec}$ faster compared to the maximum pitch angle. Thus, the distance between the water bladders influences the time taken to accomplished the desired pitch and roll angles.

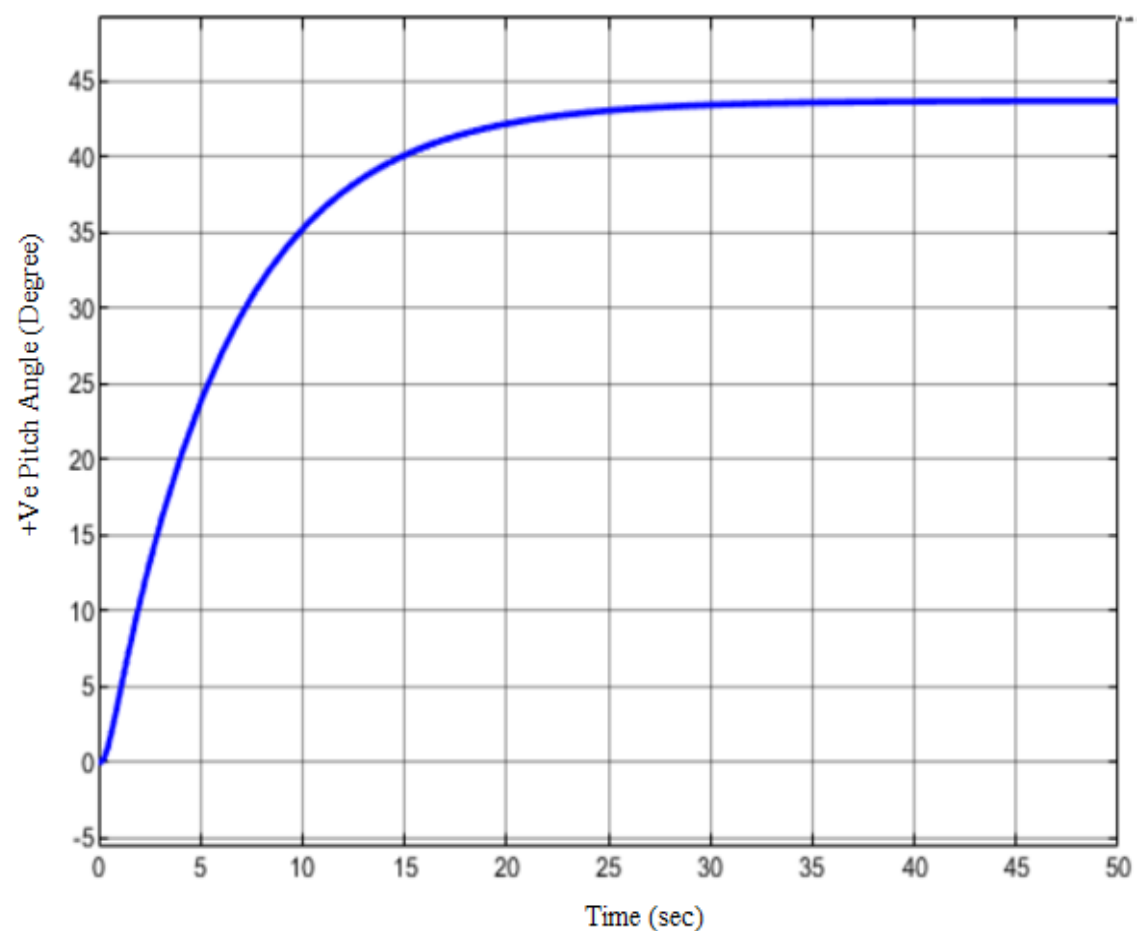

(a)

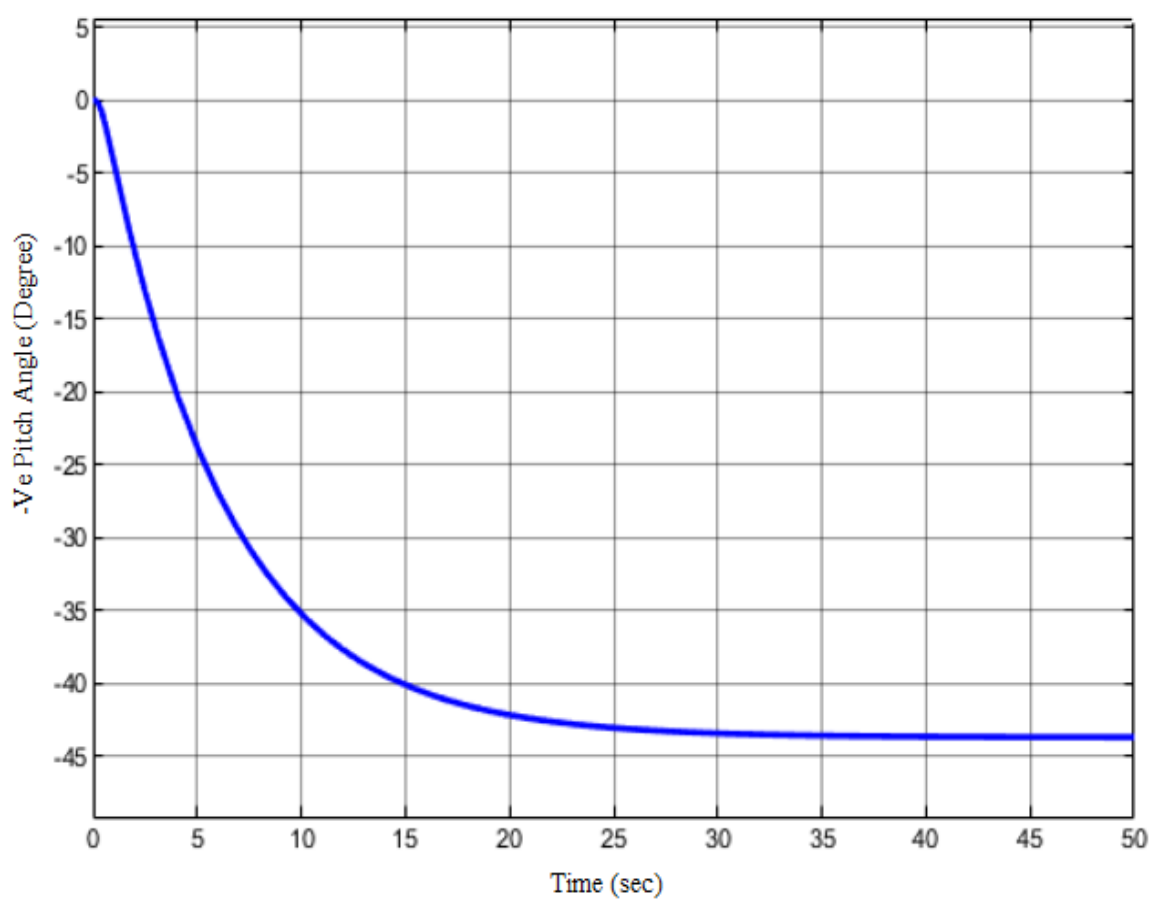

(b)

Fig. 10. Pitch angle (degree) vs time (sec); (a) + Ve pitch angle (degree), (b) - Ve pitch angle (degree) 


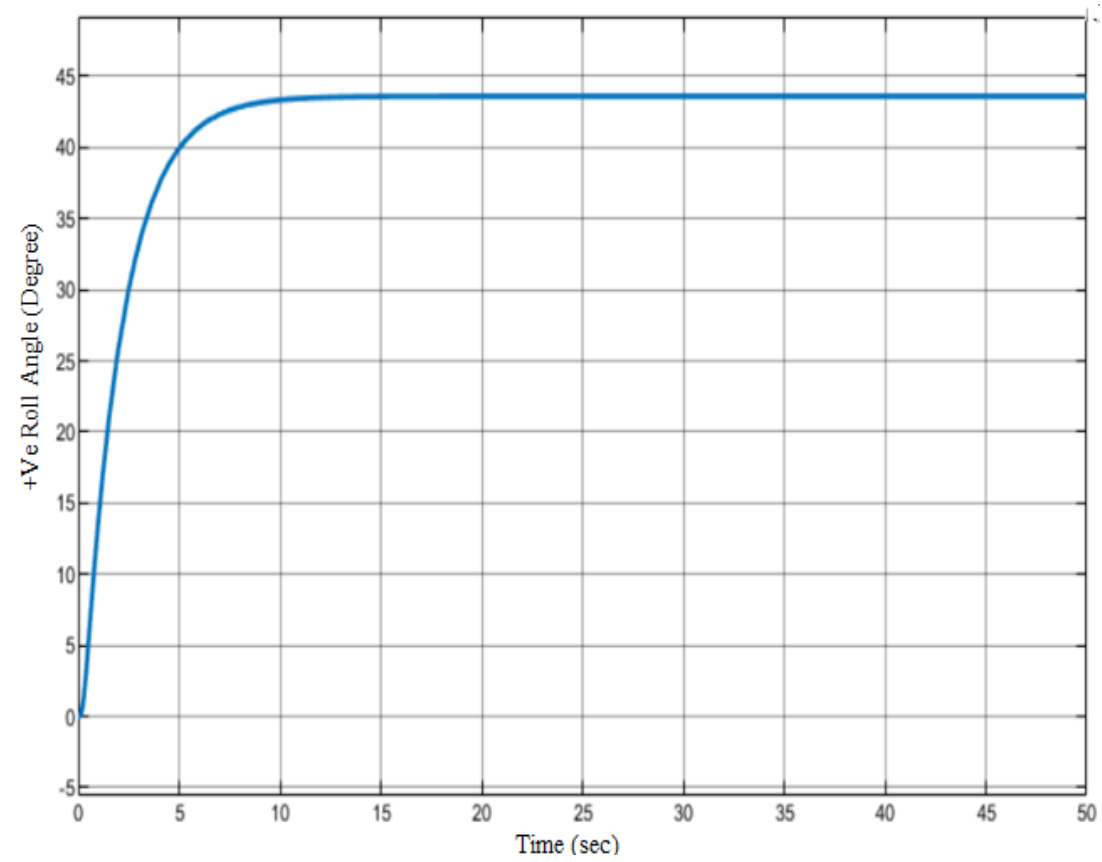

(a)

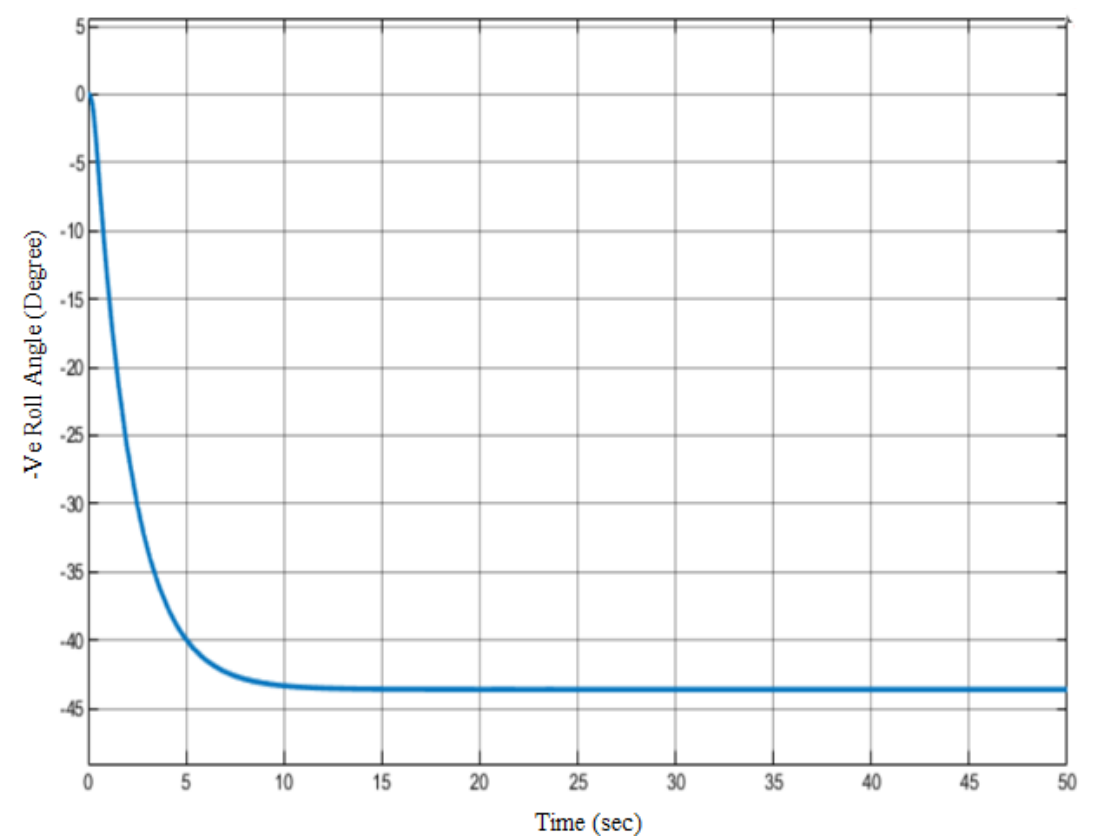

(b)

Fig. 11. Roll angle (degree) vs time (sec); (a) + Ve roll angle (degree), (b) - Ve roll angle (degree)

To validate the accuracy of the glider angle obtained through the Simulink model, the roll angle was compared with the experimental result, as shown in Figure 12. The roll angle is significant to altering the gliding trajectory and maintain the stability of the gliding motion. The maximum roll angle was 42.3 degrees after 15 seconds, which is less than $3 \%$ of the roll angle error compared to the simulation data. The data validation at the same time instant produced less than $10 \%$ of the roll angle error, due to the glider not being perfectly balanced in the water while the simulation assumes perfect balance and symmetry. However, when compared to the USM glider, the UTP glider's roll angle data is more reliable between the experimental and simulation data. 


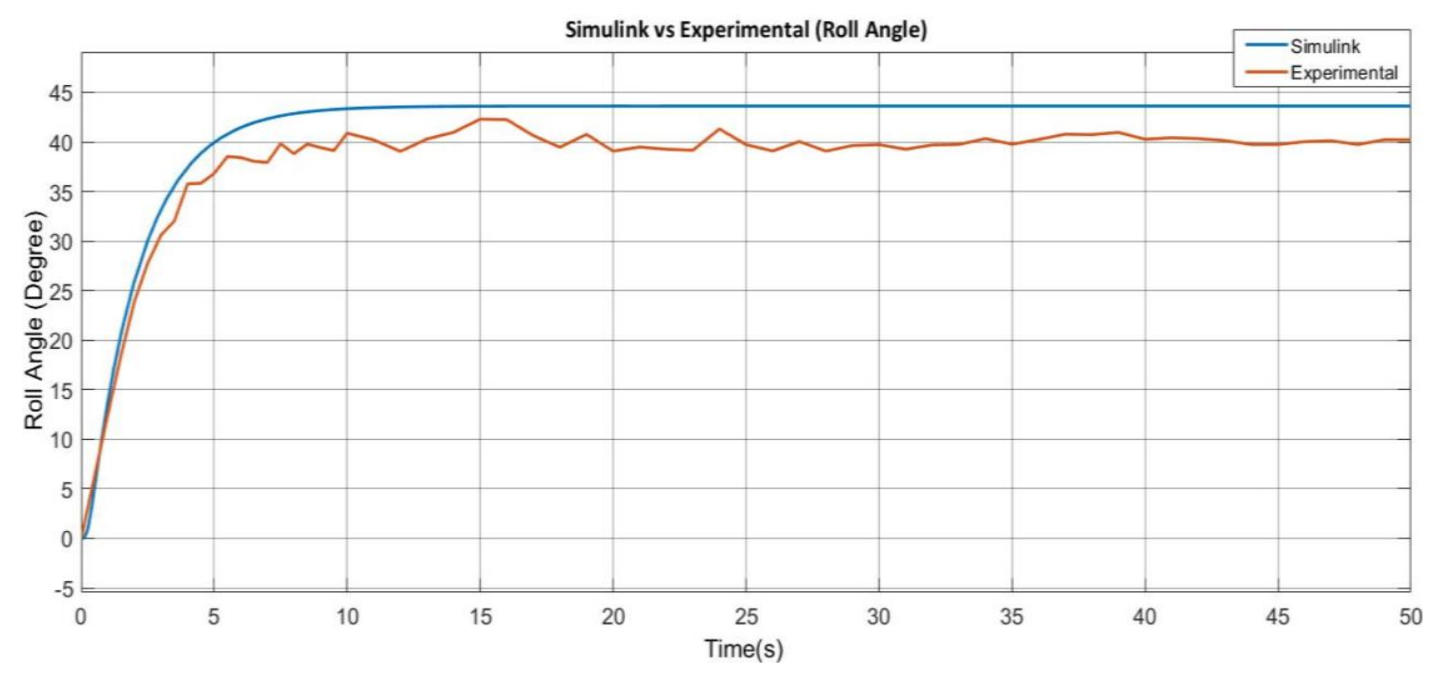

Fig. 12. Comparison of roll angle experimental and simulation results

\subsubsection{The relation between pitch rate with the pump flow rate}

In this study, a 2.5LPM pump flow rate was set and compared with the actual pitch rate, as shown in Figure 13. During testing, the pitch is affected by environmental interruptions. Therefore, there is an error of $15 \%$ between the experimental pitch rate and the simulation result. The highest pitch rate was achieved within 2 seconds with a peak experimental and simulation pitch rate of $2.70 \mathrm{E}-01$ and 2.67E-01 with an error of $1.1 \%$ for the highest pitch rates. On the other hand, the pitch stopped time at $33 \mathrm{sec}$ reflects the measurement sampling of the individual water column. The experimental test demonstrates that the glider model with a water pump system is a viable alternative to existing coupled control methods.

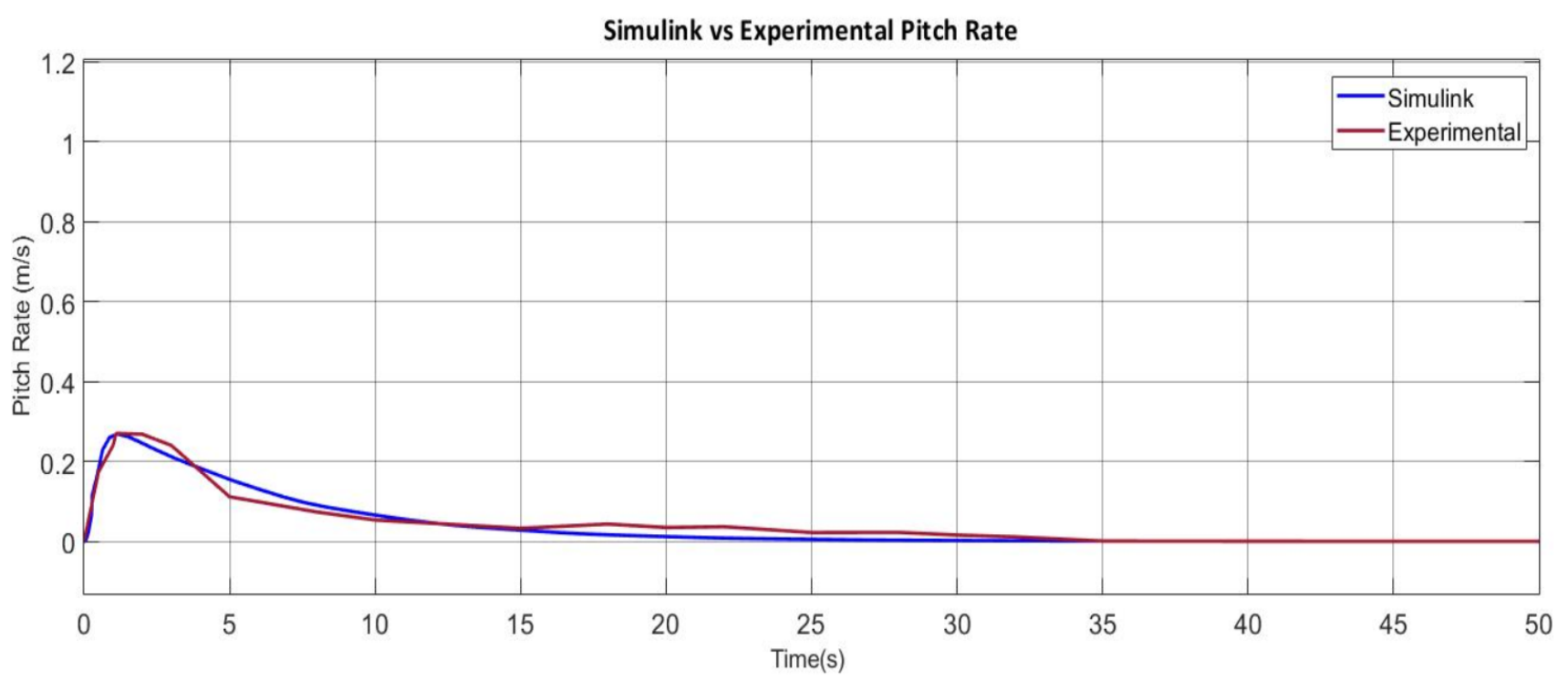

Fig. 13. Comparison of the pitch rate experimental and the simulation results

As for the prime manoeuvering system, the dynamic characteristics of the glider need to be considered to evaluate the pitch of the glider. Thereby, the dynamic equations were applied in order to obtain the pitch rate to the corresponding pump rate of 2.5LPM,5LPM,7.5LPM, and 10LPM. Although all the four pump rates were sampled at the same time instant, it shows the variation in the flow rate. Figure 14 illustrates that the pitch rate increases gradually with increasing the pump 
rate. As expected, the $2.5 \mathrm{LPM}$ pump rate results in a lower pitch rate compared to the $10 \mathrm{LPM}$ pump rate, which is $2.64 \mathrm{E}-01 \mathrm{~m} / \mathrm{s}$ and $1.07 \mathrm{~m} / \mathrm{s}$ respectively, a difference of $77 \%$. On average, the highest pitch rate was achieved within 2 seconds, with the rise-time varying for different pump rates. The UTP glider has a better pitch rate compared to legacy gliders, with a $10.8 \%$ lower pitch rate compared to the Hybrid Glider model.

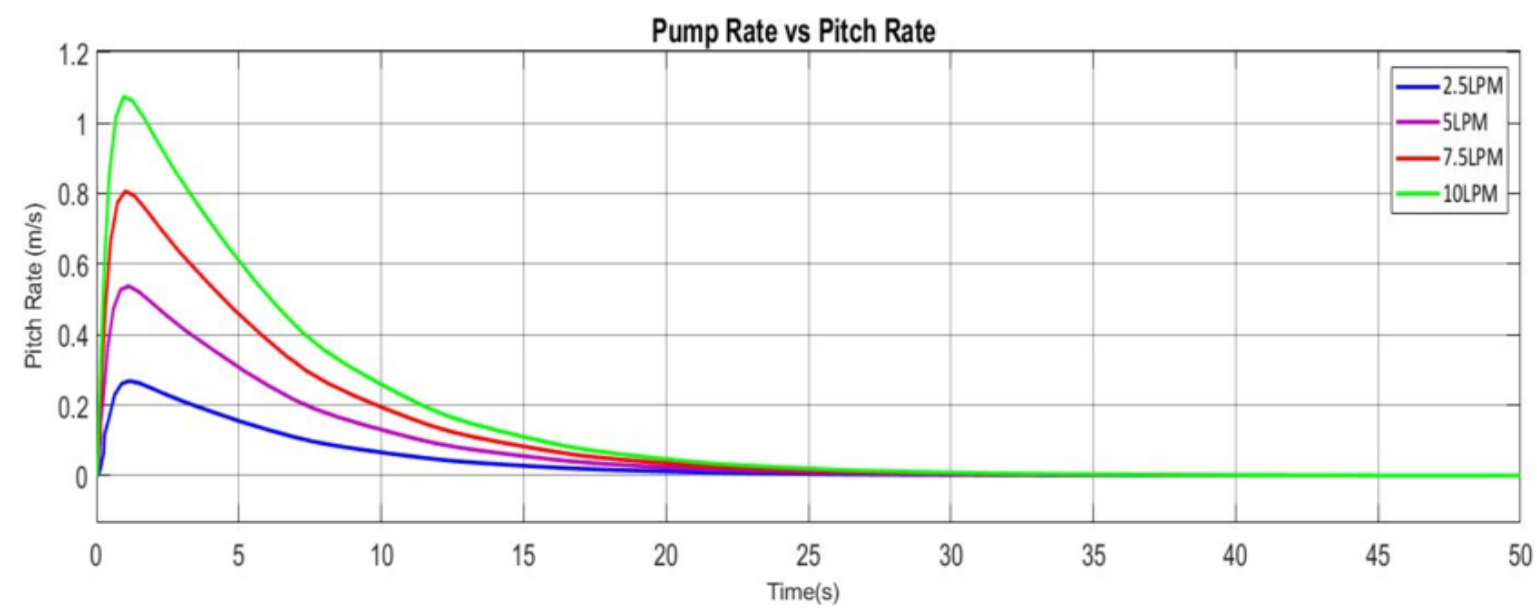

Fig. 14. Pitch rate simulation for the 2.5LPM, 5LPM, 7.5LPM, and 10LPM pump flow rate

\subsubsection{The relation between roll rate with the pump flow rate}

Aside from the roll angle, the roll rate has a key role to evaluate the rolling behavior of the underwater glider. Pump rates of 2.5LPM, 5LPM, 7.5LPM, and 10LPM were simulated to determine the corresponding rolling rate $(\mathrm{rad} / \mathrm{s})$, as shown in Figure 15 . Similar to the pitch motion, the roll rate is affected by the pump rate. Whereby, 2.5 LPM pump rate results in a $73.7 \%$ lower roll rate compared to the 10 LPM pump rate, thus the rise-time fluctuating for different pump rates. Followed by the roll angle, the roll rate was completed within the $13^{\text {th }}$ to $15^{\text {th }} \mathrm{sec}$. This roll response is consistent between experimental and simulation data.

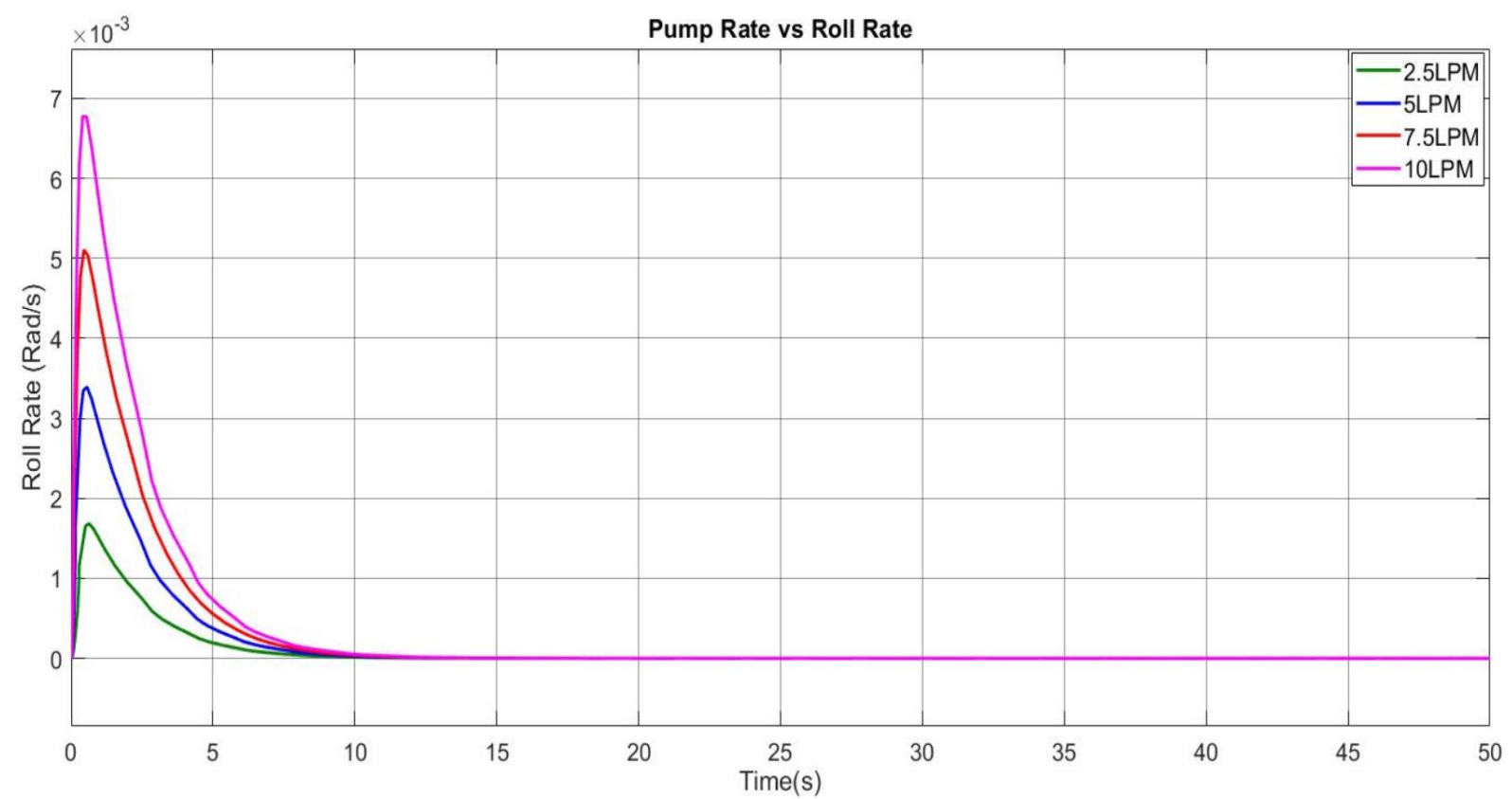

Fig. 15. Roll rate simulation for the 2.5LPM, 5LPM, 7.5LPM, and 10LPM pump flow rate 
Figure 16 shows, the relationship between maximum pitch and roll rate with the applied pump rate. During the pitch, water mass is displaced along the ' $x$ ' axis, while for roll, water mass is shifted along with the ' $y$ ' axis of the Body's Fixed coordinate system. Both pitch and roll rates are directly proportional to the pump rate, with pitch and roll rates increasing when the pump rate increased. Therefore, both are the key factors to evaluate the performance of the UTP glider. During the experiment, we observed these pitch and roll rates were influenced by the dynamic stability of the glider in the real environment.

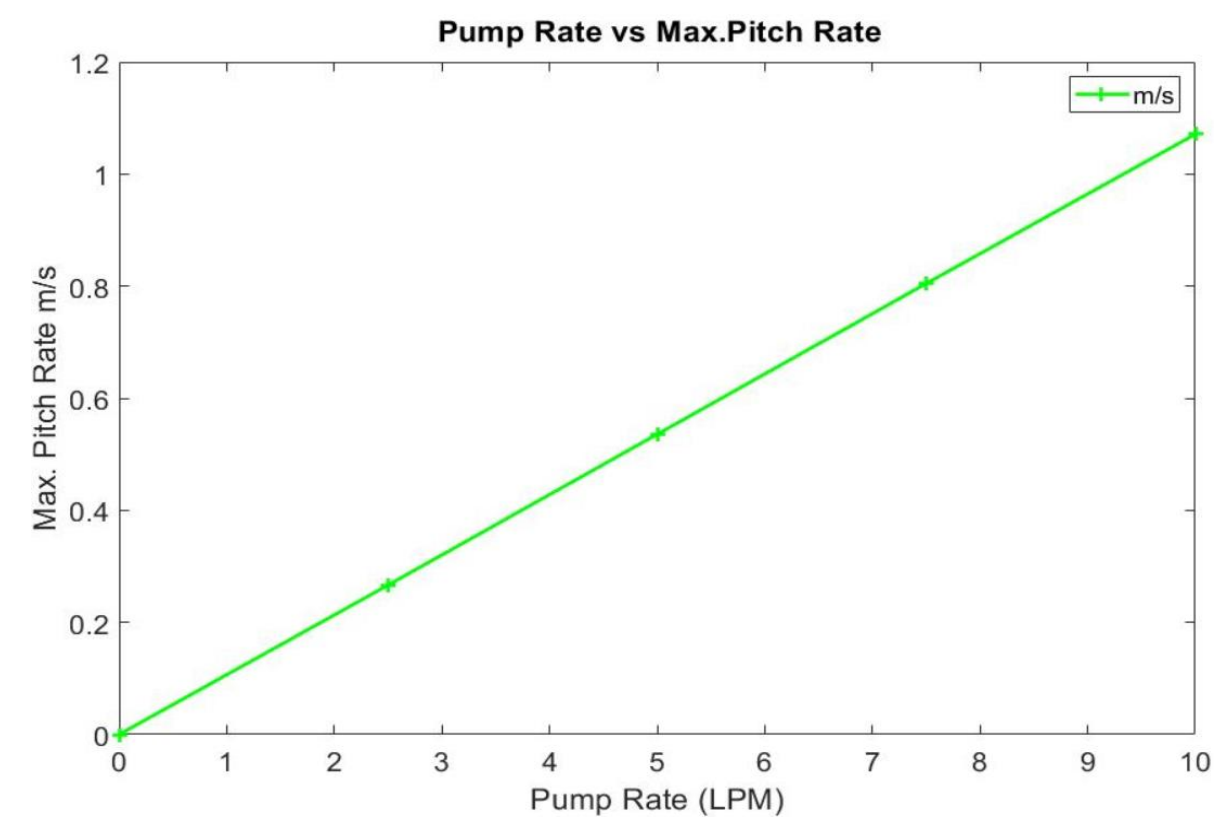

(a)

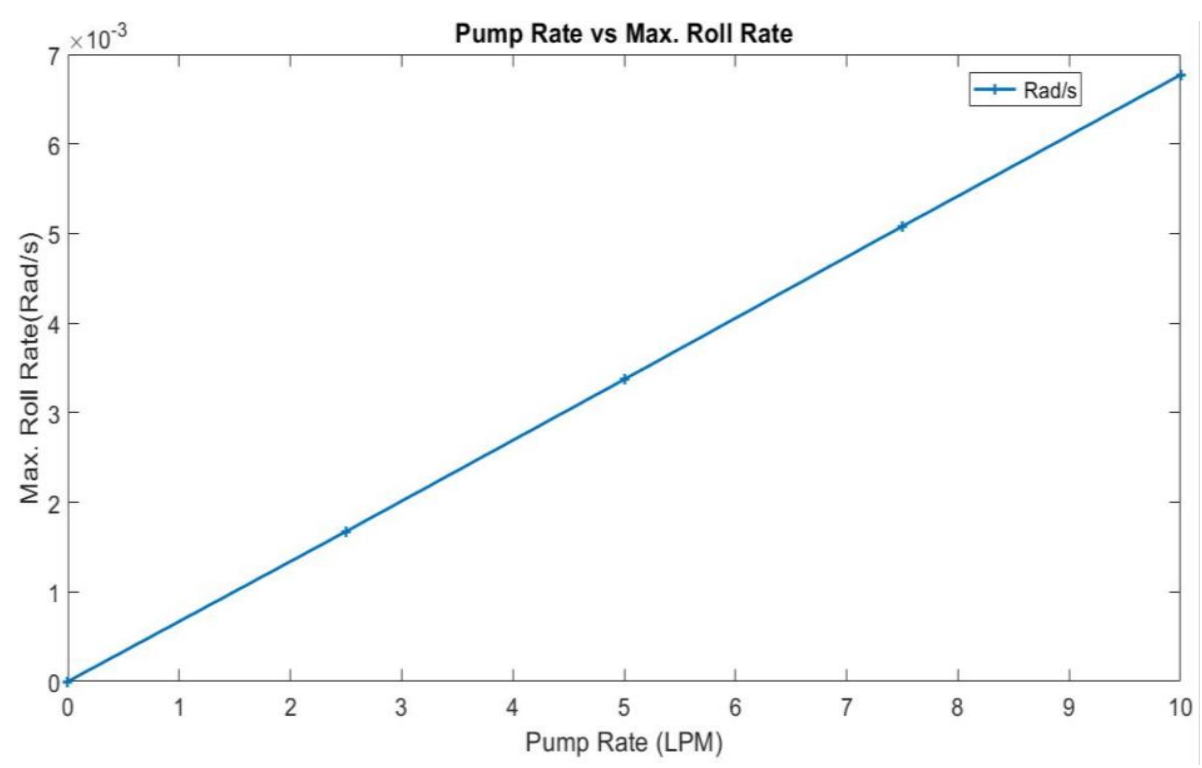

(b)

Fig. 16. Comparison of the max. pitch and roll rate with the corresponding pump rate; (a) Max.pitch rate (m/s), (b) Max.Roll Rate (Rad/s) 


\section{Conclusions}

In this study, the relationship between pump flow rate with the pitch and roll rate was investigated. Based on the simulation results, the glider's pitch and roll rate increases when the pump rate is increased. Subsequently, the experimental result shows that the glider can achieve the highest pitch rate which is $0.24 \mathrm{~m} / \mathrm{s}$. A maximum pitch angle 43.5-degree and a roll angle of 43.6 -degree results from the Simulink model and was validated experimentally. The glider can pitch and roll without the use of the conventional coupled system.

\section{Acknowledgment}

This research was supported by Universiti Teknologi PETRONAS, Malaysia.

\section{References}

[1] Kalvin, Roman, Juntakan Taweekun, Muhammad Waqas Mustafa, Faisla Ishfaq, and Saba Arif. "Design and Fabrication of Under Water Remotely Operated Vehicle." Journal of Advanced Research in Fluid Mechanics and Thermal Sciences 82, no. 1 (2021): 133-144. https://doi.org/10.37934/arfmts.82.1.133144

[2] Yusof, Ahmad Anas, Mohd Khairi Mohamed Nor, Shamsul Anuar Shamsudin, Mohd Rizal Alkahari, Mohd Shahrieel Mohd Aras, Mohamad Riduwan Md. Nawawi, Mohd Zaidi Mohd Tumari, and Mohammad 'Afif Kasno. "Lessons learned from UTeM Autonomous Underwater Vehicle Competition Initiatives." Progress in Fluid Power, Mechanisations and Mechatronics 2, no. 1 (2018): 10-26.

[3] Schofield, Oscar, Josh Kohut, David Aragon, Liz Creed, Josh Graver, Chip Haldeman, John Kerfoot et al. "Slocum gliders: Robust and ready." Journal of Field Robotics 24, no. 6 (2007): 473-485. https://doi.org/10.1002/rob.20200

[4] Javaid, Muhammad Yasar, Mark Ovinis, Nagarajan Thirumalaiswamy, Fakhruldin BM Hashim, Barkat Ullah, and Adi Maimun. "Numerical investigation on the hydrodynamic characteristics of an autonomous underwater glider with different wing layouts." ARPN Journal of Engineering and Applied Sciences 12, no. 8 (2017): 2588-2592.

[5] Jeong, Sang-Ki, Hyeung-Sik Choi, Jae-Hyun Bae, Sam-Sang You, Hyeon Seung Kang, Shin-Je Lee, Joon-Young Kim, Dong-Hee Kim, and Yong-Kuk Lee. "Design and control of high speed unmanned underwater glider." International Journal of Precision Engineering and Manufacturing-Green Technology 3, no. 3 (2016): $273-279$. https://doi.org/10.1007/s40684-016-0035-1

[6] Rudnick, Daniel L., Russ E. Davis, Charles C. Eriksen, David M. Fratantoni, and Mary Jane Perry. "Underwater gliders for ocean research." Marine Technology Society Journal 38, no. 2 (2004): 73-84. https://doi.org/10.4031/002533204787522703

[7] Sherman, Jeff, Russ E. Davis, W. B. Owens, and J. Valdes. "The autonomous underwater glider" Spray"." IEEE Journal of Oceanic Engineering 26, no. 4 (2001): 437-446. https://doi.org/10.1109/48.972076

[8] Eriksen, Charles C., T. James Osse, Russell D. Light, Timothy Wen, Thomas W. Lehman, Peter L. Sabin, John W. Ballard, and Andrew M. Chiodi. "Seaglider: A long-range autonomous underwater vehicle for oceanographic research." IEEE Journal of Oceanic Engineering 26, no. 4 (2001): 424-436. https://doi.org/10.1109/48.972073

[9] Ziaeefard, Saeedeh, Brian R. Page, Anthony J. Pinar, and Nina Mahmoudian. "Effective turning motion control of internally actuated autonomous underwater vehicles." Journal of Intelligent \& Robotic Systems 89, no. 1 (2018): 175-189. https://doi.org/10.1007/s10846-017-0544-3

[10] Javaid, Muhammad Yasar, Mark Ovinis, T. Nagarajan, and Fakhruldin BM Hashim. "Underwater gliders: a review." In MATEC Web of Conferences, vol. 13, p. 02020. EDP Sciences, 2014. https://doi.org/10.1051/matecconf/20141302020

[11] Niu, Wen-dong, Shu-xin Wang, Yan-hui Wang, Yang Song, and Ya-qiang Zhu. "Stability analysis of hybrid-driven underwater glider." China Ocean Engineering 31, no. 5 (2017): 528-538. https://doi.org/10.1007/s13344-017-0061$\underline{y}$

[12] Zhou, Mingxi. "The approach of improving the roll control of a slocum autonomous underwater glider." PhD diss., Memorial University of Newfoundland, 2012.

[13] Zhang, Feitian, Osama Ennasr, Elena Litchman, and Xiaobo Tan. "Autonomous sampling of water columns using gliding robotic fish: Algorithms and harmful-algae-sampling experiments." IEEE Systems Journal 10, no. 3 (2015): 1271-1281. https://doi.org/10.1109/JSYST.2015.2458173

[14] Ji, Dae-Hyeong, Hyeung-Sik Choi, Jin-Il Kang, Hyun-Joon Cho, Moon-Gap Joo, and Jae-Heon Lee. "Design and control of hybrid underwater glider." Advances in Mechanical Engineering 11, no. 5 (2019): 1687814019848556. https://doi.org/10.1177/1687814019848556 
[15] Isa, Khalid, and M. R. Arshad. "Experimental analysis of homeostatic-inspired motion controller for a hybrid-driven autonomous underwater glider." Jurnal Teknologi 74, no. 9 (2015): 51-63. https://doi.org/10.11113/it.v74.4808

[16] Yasar, Javaid Muhammad, Ovinis Mark, T. Nagarajan, Syed Saad Azhar Ali, and Barkat Ullah. "Study on wing aspect ratio on the performance of a gliding robotic fish." In Applied Mechanics and Materials, vol. 786, pp. 248-253. Trans Tech Publications Ltd, 2015. https://doi.org/10.4028/www.scientific.net/AMM.786.248

[17] Arima, M., N. Ichihashi, and Y. Miwa. "Modelling and motion simulation of an underwater glider with independently controllable main wings." In Oceans 2009-Europe, pp. 1-6. IEEE, 2009. https://doi.org/10.1109/OCEANSE.2009.5278267

[18] bin Ibrahim, Mohamad Faizul, Ovinis Mark, and Kamarudin bin Shehabuddeen. "An Underwater Glider for Subsea Intervention: A Technical Feasibility Study." In Applied Mechanics and Materials, vol. 393, pp. 561-566. Trans Tech Publications Ltd, 2013. https://doi.org/10.4028/www.scientific.net/AMM.393.561

[19] Ullah, Barkat, Mark Ovinis, Masri B. Baharom, Joga D. Setiawan, Syed Saad Azhar Ali, and M. Y. Javaid. "Motion control strategy of an underwater glider in the presence of external disturbances." ARPN Journal of Engineering and Applied Sciences 11, no. 22 (2006): 13031-13037.

[20] Petritoli, Enrico, Fabio Leccese, and Marco Cagnetti. "High Accuracy Buoyancy for Underwater Gliders: The Uncertainty in the Depth Control." In Selected Papers from the 2018 IEEE International Workshop on Metrology for the Sea, vol. 19, no. 1831, p. 123. MDPI, 2020. https://doi.org/10.3390/s19081831

[21] Javaid, Muhammad Yasar, Mark Ovinis, Fakhruldin Mohd Hashim, Adi Maimun, Yasser M. Ahmed, and Barkat Ullah. "Effect of water current on underwater glider velocity and range." Jurnal Teknologi 78, no. 10-4 (2016): 47-53. https://doi.org/10.11113/jt.v78.9890

[22] Zhang, Feitian, John Thon, Cody Thon, and Xiaobo Tan. "Miniature underwater glider: Design, modeling, and experimental results." In 2012 IEEE International Conference on Robotics and Automation, pp. 4904-4910. IEEE, 2012. https://doi.org/10.1109/ICRA.2012.6225264

[23] Isa, Khalid, and Mohd Rizal Arshad. "Motion simulation for propeller-driven USM underwater glider with controllable wings and rudder." In 2011 2nd International Conference on Instrumentation Control and Automation, pp. 316-321. IEEE, 2011. https://doi.org/10.1109/ICA.2011.6130179

[24] Hong, Eng You, Hong Geok Soon, and Mandar Chitre. "Depth control of an autonomous underwater vehicle, STARFISH." In OCEANS'10 IEEE SYDNEY, pp. 1-6. IEEE, 2010. https://doi.org/10.1109/OCEANSSYD.2010.5603566

[25] Singh, Yogang, S. K. Bhattacharyya, and V. G. Idichandy. "CFD approach to modelling, hydrodynamic analysis and motion characteristics of a laboratory underwater glider with experimental results." Journal of Ocean Engineering and Science 2, no. 2 (2017): 90-119. https://doi.org/10.1016/j.joes.2017.03.003

[26] Javaid, Muhammad Yasar, Mark Ovinis, Fakhruldin BM Hashim, Adi Maimun, Yasser M. Ahmed, and Barkat Ullah. "Spiraling motion of an underwater glider: dynamic modeling." ARPN Journal of Engineering and Applied Sciences 11, no. 22 (2006): 13006-13012.

[27] Fitriadhy, Ahmad, Syarifuddin Dewa, Nurul Aqilah Mansor, Nur Amira Adam, Cheng Yee Ng, and Hooi Siang Kang. "CFD Investigation into Seakeeping Performance of a Training Ship." CFD Letters 13, no. 1 (2021): 19-32. https://doi.org/10.37934/cfdl.13.1.1932

[28] Javaid, Muhammad Yasar, Mark Ovinis, Nagarajan Thirumalaiswamy, Fakhruldin Hashim, Adi Maimun, and Barkat Ullah. "Dynamic motion analysis of a newly developed autonomous underwater glider with rectangular and tapered wing." Indian Journal of Geo-Marine Sciences 44, no. 12 (2015): 1928-1936. 